\title{
Endomyocardial Biopsy Guided by Echocardiography
}

\author{
Alfredo Inácio Fiorelli, Wilson Mathias Junior \\ and Noedir Antonio Groppo Stolf \\ Heart Institute of Sao Paulo University \\ Brazil
}

\section{Introduction}

In the recent year, transcatheter endomyocardial biopsy is a procedure relatively simple that has been increasingly utilized in cardiomyopathy diagnosis. It is estimated that over 50,000 biopsies are performed annually in the United States in general to control rejection episodes after heart transplantation.

Endomyocardial biopsy plays important role in the diagnosis and treatment of adult and pediatric cardiovascular disease due to many specific myocardial disorders the etiology is seldom discovery by noninvasive testing. The indication this procedure may be especially challenging for many nonspecialists because the method is invasive and always must weigh the risks and benefits. The percutaneous transvenous endomyocardial biopsy has become the procedure safe and more convenient for rejection control after heart transplantation, histopathological diagnosis of cardiomyopathies or tumors ${ }^{1,2,3}$. The endomyocardial biopsy technique is safe in experienced hands however the method may lead to several complications, the most serious them is the right ventricle perforation with cardiac tamponade 4,5 .

Heart biopsy already experimented investigation with different methods such as: open thoracotomy ${ }^{6}$; partial extrapleural thoracotomy with resection of a rib to facilitate the exposition7; percutaneous introduction of Vim-Silverman and Menghini needle $8,9,10$; introduction of a modified Ross transseptal needle through the superior vena cava or carotid artery11; and the use of cutting blades introduced through a catheter for endomyocardial biopsy ${ }^{12}$. Unfortunately, the heart biopsy history was marked by severe complications, which included pericardial tamponade, cardiac perforation, pneumothorax and hemothorax, and eventually death. Since 1980, the technique has become routinely used.

Weinberg et al., in 1958, reported their experience with five patients who were undergone pericardial and myocardial biopsy ${ }^{13}$. The procedure was performed percutaneously under local anesthesia and the thorax was opened by resection of the fourth cartilage on the left. This invasive method did not gain ample acceptance due to high risk. The cardiac biopsy with needle through a limited thoracotomy was associated with pulmonary injuries, cardiac tamponade, coronary vessels laceration, arrhythmia, and sometimes with death. Despite these risks, direct needle biopsy was carried out in some centers. 
In 1960, Sutton and Sutton reported the use of the myocardial biopsy in 150 patients whose specimens was obtained with needle introduced percutaneously at the left ventricular apex ${ }^{14}$. The guidance was done by fluoroscopy or electrocardiography but surgical risk maintained high. Ventricular premature beats or pulsation felt through needle indicated contact with left ventricle surface. This technique was repeated experimentally with few variations by Timmis et al., in 1972, using either Vim-Silverman or Menghini needle ${ }^{15}$. An electrocardiogram electrode extension was attached at needle to help in recognition of the epicardium through the lesion current; however without risk significative reduction.

In 1962, Sakakibara and Konno became responsible for the introduction of the endomyocardial biopsy modern era with use of a flexible bioptome with sharpened cusps through transvascular approach to obtain endomyocardial tissue by a bite as opposed to cutting technique ${ }^{16}$. A long catheter was introduced into a peripheral vein or artery by dissection technique and advances to the right or left ventricle and small movable cutting jaws obtaining pieces of myocardial about $3 \mathrm{~mm}$ in diameter.

In 1965, Bulloch et al. improved the safety of cardiac biopsy proposing the use of vascular access through the right external or internal jugular vein by introduction of a capable needle of withdrawing specimens from the right interventricular septum ${ }^{17}$.

In 1972, Caves et al. at Stanford University developed another bioptome model that is in use until today for assessment of cardiac allograft rejection. The bioptome contains a moving jaw so that the longer and thinner is used for left ventricular biopsy and the shorter and thicker for right ventricular biopsy ${ }^{18}$. In the same year, Shirey et al., presented experience with left ventricle biopsy ${ }^{19}$.

In 1973, Ali et al., publishing experience with the technique of Sakakibara and Konno for right ventricular endomyocardial biopsy by transvenous access employed in 28 patients with a variety of myocardial diseases of known and unknown etiology 20 .

In 1974, Richardson reported another transvascular technique that gained wide acceptance with use of a modified Olympus bronchoscope biopsy forceps, called the King's College endomyocardial bioptome, introduced through a long sheath for either left or right ventricular biopsy ${ }^{21}$.

In 1980, Kawai proposed the use of a new flexible model catheter to able of monitoring simultaneously the intraventricular electrocardiogram 22 .

Table 1 shows the main diagnostic finding in endomyocardial biopsy and the main indications to endomyocardial biopsy at Heart Institute of Sao Paulo University include:

1. Assessment and management of graft rejection after heart transplantation;

2. Remission control of Chagas' disease reactivation after specific therapy administration, in general after heart transplantation;

3. Evaluation and diagnosis of the cardiomyopathies with unknown etiology;

4. Diagnostic and orientation of the infectious myocarditis, inflammatory, drug induced, and others;

5. Evaluation and management of malignant ventricular arrhythmias with unknown etiology;

6. Evaluation and orientation of restrictive cardiomyopathies with unknown etiology;

7. Etiologic diagnosis of the intracardiac tumor mass;

8. Cardiomyopathy evaluation after use of immunosuppressive therapy;

9. Controlled research protocols approved by the ethics committee and research of the institution. 


\section{Inflammatory or Immunology}

- Heart allograft rejection

- Chagas 'disease reactivation

- Myocarditis

- Cytomegalovirus infection

- Toxoplasmosis

- Sarcoidosis

- Rheumatic myocarditis

- Eosinophilic myocarditis

- Kawasaki' disease

- Differentiation between restrictive cardiomyopathy and pericarditis Ischemic

- $\quad$ Acute or chronic ischemic cardiomyopathy

- Shönlen-Henoch purpura

\section{Infiltrative}

- Amyloidosis

- Hemochromatosis

- Glycogen deposit disease

- Fabry' disease

- Gaucher' disease

\section{Degenerative}

- Idiopathic cardiomyopathy

- Drug-induced cardiomyopathy

- Actinic cardiomyopathy

\section{Tumor}

- Primary cardiac neoplasm

- Metastatic cardiac neoplasm

Table 1. Principal findings of the endomyocardial biopsy

\section{Technique of the endomyocardial biopsy}

\subsection{Special care}

All biopsies must be performed with cardiac rhythm control, blood pressure, and continuous oxygen saturation. Patients with coagulopathies, thrombocytopenia, or under use of anticoagulant agents or antiplatelet should be well analyzed before biopsy to avoid hematoma formation and bleeding. The patients must be informed about all procedure stages and that during the withdrawal of myocardial fragment they may have a temporary pulling painful sensation.

No premeditation is given for routine biopsy either child as adult patient. To adult patient is not necessary the venous access temporary maintenance or sedation and the biopsies are usually performed with local anesthesia. Eventually in adolescent patients may be necessary a small sedation to comfort.

To patients with venipuncture fear may be utilized anesthetic cream existing market and which contains lidocaine and prilocaine under the trade name EMLA cream ${ }^{\mathrm{TM}}$ (an abbreviation for Eutectic Mixture of Local Anesthetics). To be effective EMLA cream ${ }^{\mathrm{TM}}$ must be applied topically in puncture site two hours before to reduce the procedure discomfort.

Patient is encouraged usually to have a regular meal and if possible increase oral fluid amount up to 6 or 8 hours prior to biopsy. This maneuver is not mandatory but may facilitate the puncture. To infants and children this fasting period is minor and they should receive parenteral hydration by dehydration possibility and hypoglycemia.

However, in children or pediatric patients require sedation and general anesthesia which must be accomplished with all cares that cover this procedure. In these cases the patient oxygenation must be ensured by mechanical ventilation through endotracheal intubation or laryngeal mask airway. The pediatric patients with low ejection fraction have an increased surgical risk and care must be redoubled.

It is recommended that the endomyocardial biopsy should not be performed without a prior echocardiographic analysis, especially in pediatric patients or in diagnostic investigation of 
dilated cardiomyopathies. Echocardiography that will be utilized as guide at endomyocardial biopsy cannot be the first echocardiographic exam accomplished in the patient because it is very important to procedure planning the prior knowledge of anatomy and heart function.

It should be taken great care with the air inadvertent entry through sheath to the right heart chambers by air embolization possibility to pulmonary trunk with consequent decrease of the cardiac output, or to systemic circulation in cases with intracardiac shunts.

Endomyocardial biopsies can be performed through the following venous access or arterial: subclavian, jugular or femoral however these two last approaches are more frequently utilized. Subclavian access rarely is employed because the possibility of severe vascular injuries is greater. The procedure is more frequently performed at cardiac catheterization laboratory and uses the fluoroscopic to guide endomyocardial biopsy. But 2 twodimensional echocardiography almost always offers additional resource, either alone or combined with fluoroscopy.

In patients with multiples previous biopsies the passage of dilators with caliber gradually increased will facilitate the placement of the sheath. Venacavography realized prior in patients with antecedents of the venous thrombosis, presence of intravenous catheters or venous puncture attempts without success should be seen before biopsy to avoid accidents (Figure 1).

All the recommendations above are strongly emphasized mainly to critical patients with decompensated heart failure or pediatric patients. The cares must also be extended to the place where the biopsy will be performed as well as necessary material and equipment (Table 2). This procedure is only a diagnostic exam easily executable; however it is an invasive method of risk. Nevertheless, once when the preconized classic principles are rigorously respected, the endomyocardial biopsy evolves low values of morbidity and mortality.

\section{Emergence Material and Cardiovascular Control}

- Cardiac rhythm control, noninvasive blood pressure and $\mathrm{O}_{2}$ Saturation.

- Portable Cardiac Defibrillator.

- Fluoroscopy or Disposable Two-dimensional Echocardiography.

- Temporary Pacemaker Generator and Electrode.

- Material to Pericardiocentesis and Pericardial Drainage.

- Drugs and Equipments to Cardiovascular Reanimation.

\section{Material to Endomyocardial Biopsy Realization}

- $\quad$ Sterile Surgical Drapes and Gowns.

- Antiseptic, Lidocaine $2 \%$ without vasoconstrictor, Saline Solution, and Heparin.

- $\quad 10 \mathrm{~mL}$ and $20 \mathrm{~mL}$ Syringes, Gauze, Bandages and Hypodermic Needles.

- Material to Vascular Puncture: Surgical knife, Needle punctures 5Fr, 7Fr, 8Fr or 9Fr, Guidewire, Dilator, Sheath and Bioptome.

- Surgical instruments: Anatomical forceps, Scissors, Needle holder, Forceps type Halstead and Backaus.

Table 2. Material and Equipment utilized during Endomyocardial Biopsy 


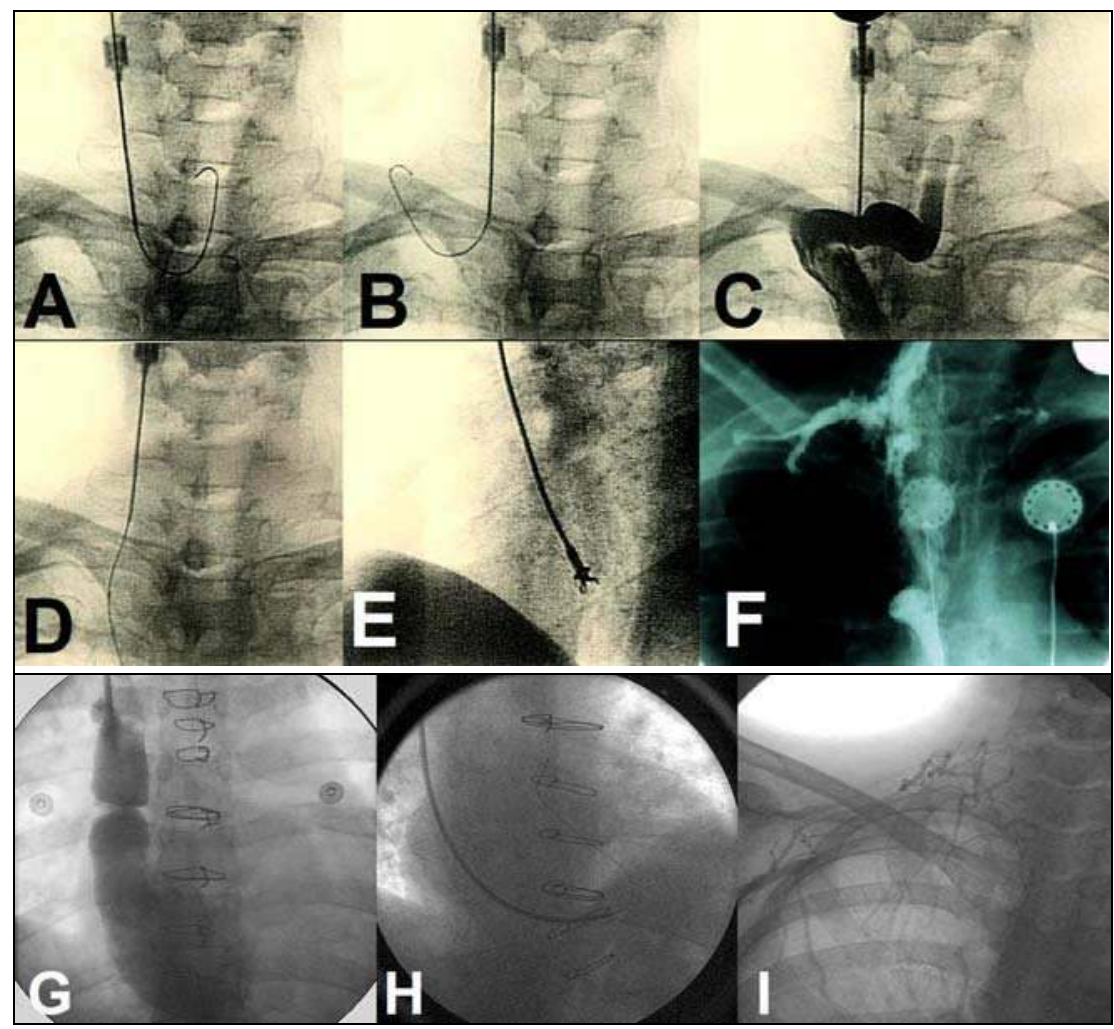

Fig. 1. A - Attempted passage of guidewire through the right internal jugular vein. BGuidewire deviated to the right subclavian vein. C - Contrast injection showing the venous anatomy. D - Passing of the guidewire after needle to be gently sloping. E - Introduction of the bioptome with two jaw. F - Superior vena cava with obstruction. G - Superior vena cava anastomosis with stenosis after cardiac transplantation by bicaval technique. $\mathrm{H}$ - Sheath positioned into right ventricle with the aid of the guidewire. I - Upper venous system with obstruction

\subsection{Bioptomes}

Currently, there are disposable bioptomes and sheaths available for percutaneous insertions and biopsy either left ventricle as right. Over the years the development of modern devices became the cardiac biopsy of a high risk technique to an insurance procedure and simple.

Two basic types of bioptomes are available concerning the format with pre-shaped distal end (stiff shape - Konno, and Caves-Shultz bioptome) and unshaped maintained straight (floppy shaft - King, Cordis, Cook bioptome). The pre-shaped bioptome does not require long sheath or pre-shaped it can be short and straight because the bioptome curvature allows easily the entry into intraventricular chamber. Pre-shaped bioptomes have greater stiffness and offer better control to operator during biopsy. The forceps curvature angle can be modified to facilitate the passage of the instrument across tricuspid valve guiding 
the forceps against interventricular septum. Table 3 shows main bioptomes commercially available.

On the other hand, the straight bioptome necessitates pre-shaped long sheath to locate the forceps tip against interventricular septum. The pre-shaped long sheath can be located in intraventricular cavity by long guidewire or fluid filled catheter with or without balloontipped. The sheath maintenance into ventricular cavity has as advantage main the quick positioning of the forceps; however this attitude may facilitates the development of arrhythmias and the ventricular perforation. In general the pre-shaped bioptomes are used in jugular approach or subclavian and straight bioptomes in femoral approach.

It is possible to find in the market either disposable bioptome as reusable to be utilized for any conventional access approach and ventricular chambers being that the femoral vein requires a long sheath. Right ventricular endomyocardial biopsy can be performed percutaneously from one of the following approaches: internal jugular, subclavian or femoral veins. Left ventricular endomyocardial biopsy is normally performed retrograde access from one of the femoral veins.

Both fluoroscopy as echocardiography can be used to guidance during endomyocardial biopsy for any approach differing only bioptome kind and sheath. The bioptome can have one or two articulated jaws (Figure 2).

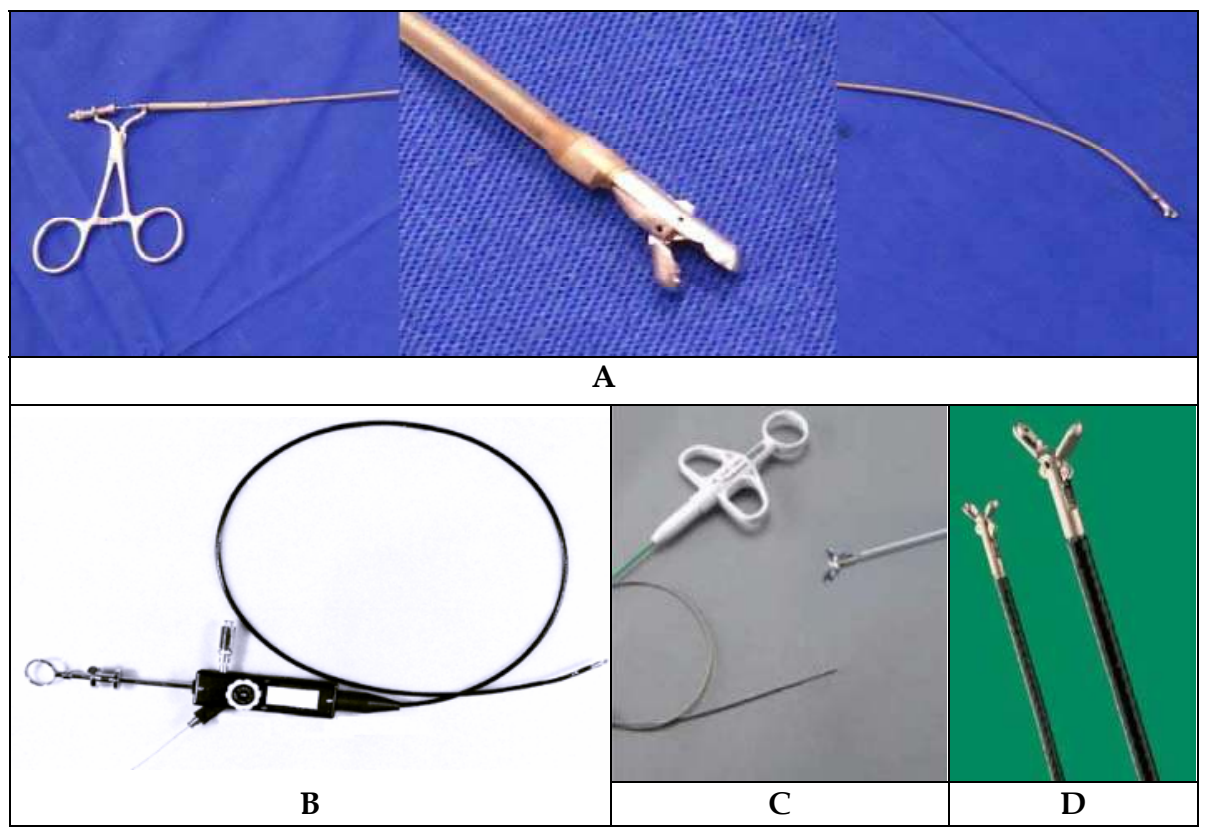

Fig. 2. A - Caves-Shultz bioptome is pre-shaped and has only one articulated jaw while the other is fixed and the introduction into cardiac chamber is done through a sheath. Jaw open. B - Kawai-model ${ }^{\circledR}$ flexible bioptome is straight and has a stainless steel shaft. It has two articulated jaws and need of a long sheath-guiding catheter introduced into ventricular chamber. C - Cook ${ }^{\circledR}$ straight bioptome. D - Straight bioptome with two articulated jaw requires a pre-shaped sheath. Jaws open 


\begin{tabular}{|c|c|c|c|c|}
\hline \multirow{2}{*}{ Model } & \multicolumn{2}{|c|}{ Jaw } & \multirow{2}{*}{$\begin{array}{c}\text { Flexible } \\
\text { Shaft } \\
\text { Length }(\mathrm{cm})\end{array}$} & \multirow{2}{*}{ Reusable } \\
\hline & size $(\mathrm{Fr})$ & Articulated & & \\
\hline $\begin{array}{l}\text { Scholten } \\
\text { Bioptome }{ }^{\circledR}\end{array}$ & $\begin{array}{c}5.0,6.5,8.0 \\
\text { and } 9.0\end{array}$ & 1 & 50 and 100 & yes \\
\hline Novatome $^{\mathrm{TM}}$ & $\begin{array}{c}6.0,7.0,8.0 \\
\text { and } 9.0\end{array}$ & 1 & 50 and 100 & no \\
\hline Cordis ${ }^{\circledR}$ & $\begin{array}{c}5.4,7.0 \text { and } \\
7.5\end{array}$ & 2 & 50 and 104 & no \\
\hline SparrowHawk® & 6.0 & 2 & 50 & no \\
\hline Cook® & 3.0 and 5.2 & 2 & 60 and 120 & no \\
\hline
\end{tabular}

Table 3. Characteristics of some bioptomes commercially available

\subsection{Internal jugular vein approach}

The right internal jugular vein is the most common percutaneous access site for right ventricular endomyocardial biopsy. Patient is placed on supine position with the neck extended and the head should be turned to the left about 45 degree to facilitate venous puncture site. The skin of the surgical region receives conventional asepsis and surgical drapes are positioned comfortably.

It is very important careful identification of the triangle formed by the medial heads and lateral of the sternocleidomastoid muscle and the clavicle because the puncture is performed at upper vertex this triangle in direction to the ipsilateral nipple. During the needle introduction is performed anesthesia with lidocaine and the intermittent aspiration confirms vein localization. Excessive use of the lidocaine may infiltrate the recurrent nervous or the carotid sheath and lead transitorily to vocal cords paralysis or Horner's syndrome respectively.

Use of ultrasound should be considered if there is any difficulty in locating the vein or artery because it facilitates the location of the blood vessel and demonstrates adjacent structures (Figure 3). Although ultrasonography is not absolutely necessary for the procedure it is a very valuable tool, mainly for patients undergo the procedure repeatedly. Valsalva maneuver or elevation of the legs may be very useful because it help to dilate the vessel and makes it more evident. Sometimes if the vein is collapsed or scarred, the use of the great gauge needle may compress the vein and make cannulation difficult and the use of thin gauge needle help to locate the vessel.

The guidewire is inserted into right internal jugular vein by standard Seldinger technique as usually is performed in all punctures to introduce intravascular catheters ${ }^{23}$. Either fluoroscopy (Figure 4E) or two-dimensional echocardiography (Figure 5) can be used to confirm appropriate wire-guide position before sheath introduction, because occasionally the wire-guide is deflected toward the arm instead of advancing toward the right atrium. 


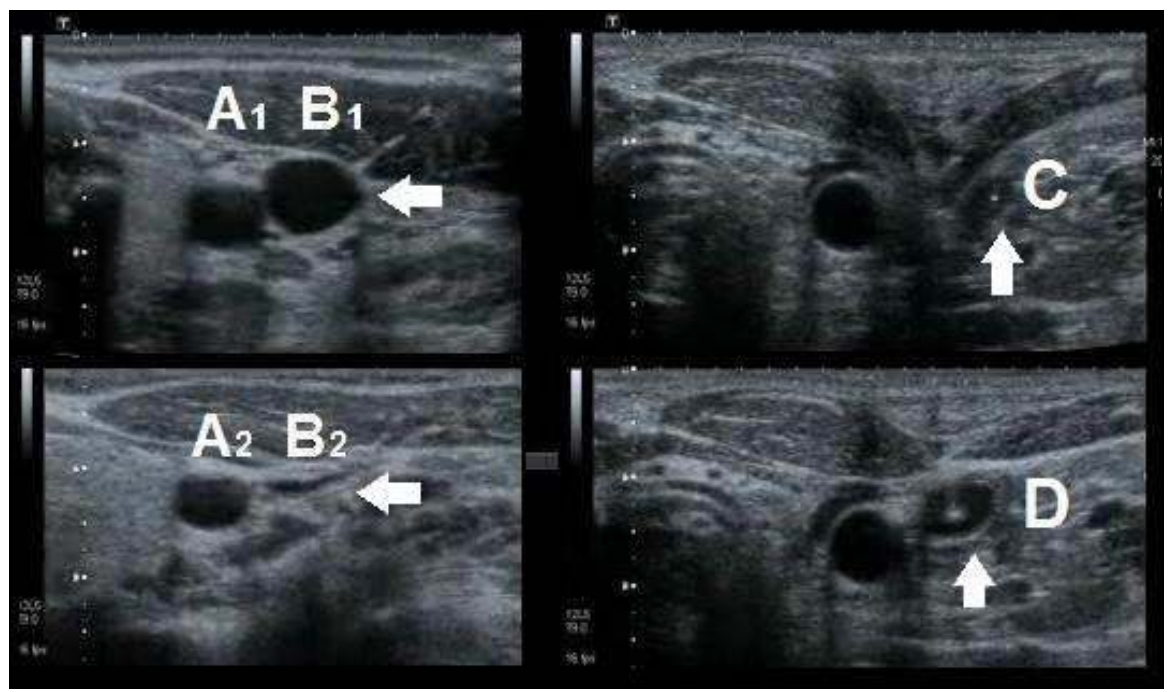

Fig. 3. The ultrasonography is a powerful resource to help the vascular puncture in difficult situations. The images above were obtained by ultrasound of the right cervical region and show the anatomical relationship between the carotid artery $(\mathrm{A})$ and internal jugular vein (B) and can be observed that the vein is much more compressible. The images to left side show venous distention with (A1B1) and without (A2B2) use of the Valsalva maneuver, respectively. $\mathrm{C}$ - During percutaneous venous puncture the image echogenic represents the correct position of the needle into internal jugular vein (arrow)

Saline solution injection through sheath produces diluted microbubbles that serve as a contrast-enhanced and facilitates intracardiac anatomy identification and the wire-guide by echocardiography. Microbubbles have a high degree of echogenicity which are able of reflect the ultrasound waves and help to differentiate the anatomical structures. Wire-guide is a metallic object and has higher echogenicity in relation to other cardiac structures being easily identified.

In Figure $4 \mathrm{~A}$ is represented the main cervical anatomical structures for orientation of the right intern jugular vein. The triangle vertex formed by sternal head muscles bundles and clavicular of the sternocleidomastoid muscle serve as orientation anatomic point to internal jugular vein puncture (Figure 4A). The needle should be oriented in direction to ipsilateral nipple forming an angle of the 45 degree with skin (Figure $4 \mathrm{~B}$ ).

An 18-gauge needle is located into right internal jugular vein through of a small incision in the skin is made with a scalpel to facilitate subsequent passage of the dilator and sheath. The needle must not be inserted in same plane of the carotid artery on the contrary should be move away from it as much as possible. If occur an inadvertent arterial puncture, the needle must be removed and an external compression is applied for 8 to 10 minutes to avoid bleeding and hematoma formation with serious consequences. Other arterial complication reported refers to carotid artery dissection or occlusion, and stroke related to emboli from thrombus or atheroma secondary to inadvertent carotid puncture.

The sheath gauge should be chosen adequately to each bioptome, for example CavesSchultz bioptome requires a $9 \mathrm{~F}$ or $8.5 \mathrm{~F}$ sheath. The sheath only should be introduced into 
vein after confirm by fluoroscopy or echocardiography that the guidewire is adequately into vein. Once finished biopsy, the sheath is removed and should be apply an external compression on the puncture site for half to one hour or more because the venous orifice left by puncture is big.

We prefer the right jugular approach to pediatric patient or infants with pre-shaped 5Frbioptome.

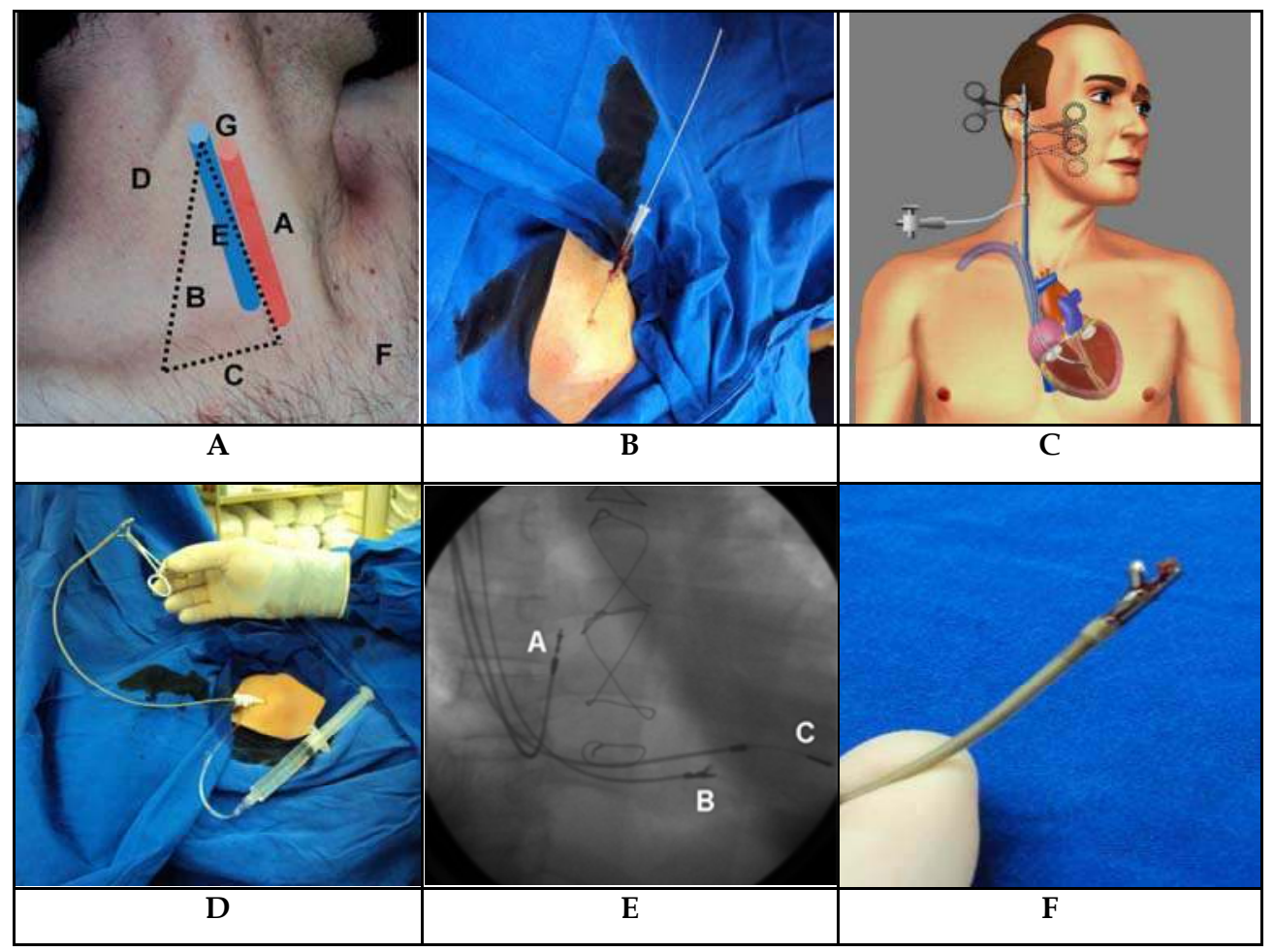

Fig. 4. Endomyocardial biopsy performed through right internal jugular vein. A - Depiction of the main cervical anatomical structures that serves to help in the right venous puncture. (A) Sternal head lateral border of the sternocleidomastoid muscle; (B) Clavicular head medial border of the sternocleidomastoid muscle; (C) Clavicule; (D) Right external jugular vein; (E) Right internal jugular vein; (F) Manubrium; and (G) Right carotid artery. B - Right internal jugular vein punctured com needle and guidewire. $C$ - Schematic diagram showing bioptome position during withdrawal of myocardial fragment. D - Pre-shaped bioptome passing through the sheath. E - Routine endomyocardial biopsy to monitoring of acute rejection after heart transplantation guided by fluoroscopy on patient with dual chamber pacemaker. (A) - Atrial electrode; (B) - Bioptome; and (C) - Ventricular electrode. F Myocardial fragment at pre-shaped bioptome

The left internal jugular vein approach is similar to above description done to the right with mirror image. Despite these considerations, the left internal jugular vein approach offers more difficulties because the trajectory since puncture site until right ventricle is more 
sinuous with critical angles in relation to right approach. Left jugular puncture allows also the deviation of the guidewire to left through subclavian vein because this latter vein receives that first perpendicularly.

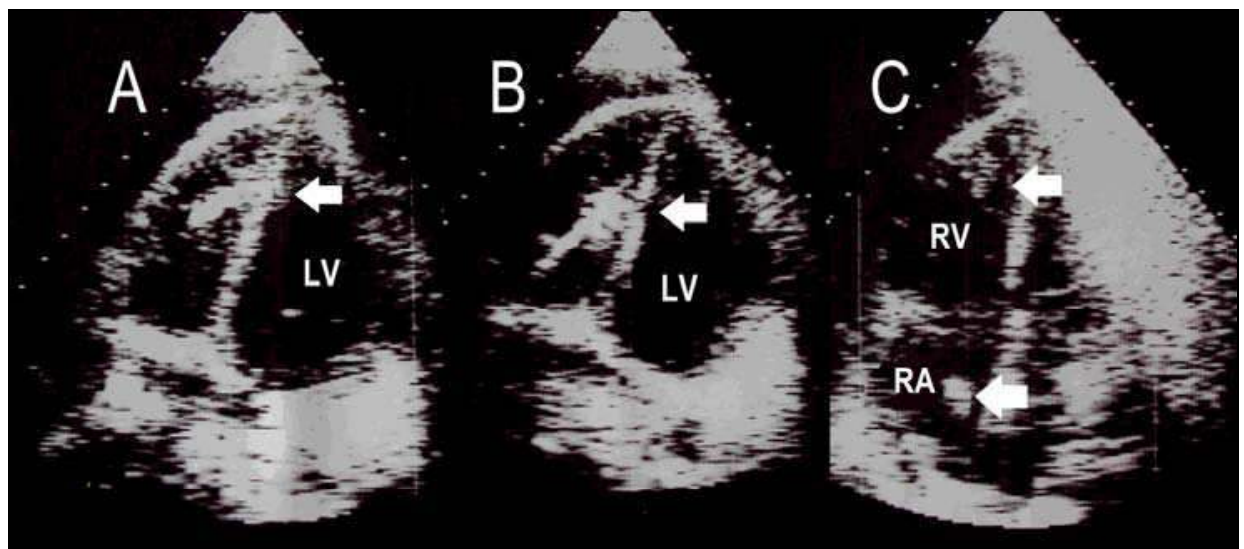

Fig. 5. Two-dimensional echocardiography images in apical four chambers used to guide the bioptome during endomyocardial biopsy. Transient echogenic image created from of saline solution infusion through sheath lateral access that facilitates the anatomical structures identification. The bioptome is adequately positioned with the tip directed to interventricular septum only in situations A and B. A - Tip of the bioptome is removing a fragment of the interventricular septum apical portion (arrow). B - Forceps open at middle portion of the interventricular septum (arrow). C - Image showing the bioptome tip in direction to right ventricle free wall (arrow). This position is not adequate for perforation risk high and in same plane can be seen also the bioptome inside the right atrium (arrow). LV - Left ventricle; RV - Right ventricle; and RA - Right atrium

\subsection{Subclavian vein approach}

Subclavian vein approach is not preferential access to perform the endomyocardial biopsy and should be used in special situations. Eventually, the internal jugular vein approach must be prevented for venous obstruction, infection, hematoma or for any other reason. So, the subclavian vein may be an alternative access to accomplish the endomyocardial biopsy. Either the left subclavian vein as right may be utilized as access approach to biopsy. The left subclavian vein generally offers less resistance to bioptome advance when compared to right due to path curvature to have major radius and without acute angle.

The subclavian vein puncture site should be more lateral than that utilized usually in venous catheters insertions to increase the puncture angle. If the right subclavian vein entry angle into superior vena cava was very acute, it may difficult the bioptome progression and with venous perforation possibility.

Before venous insertion of the dilator and sheath should be confirmed the guidewire correct position to avoid vascular injuries or put the catheter at inadequate place. The guidewire is easily detected by dimensional echocardiography as an echogenic image into superior vena cava toward right atrium. As in any vascular puncture the insertion elements must glide smoothly without offer endurance. 
In local puncture should be maintained compression for an hour or more after the sheath removal to prevent bleeding and hematoma, however this period must be further if the patient has coagulation disturbance or the puncture was difficult and complicated.

\subsection{Femoral vein approach}

Femoral vein puncture offers less technical difficulty compared to other venous access to endomyocardial biopsy (Figure 6). This approach is extremely disseminated among interventional cardiologists and it represents the preferred access them. The femoral vein approach has as main advantages the lower risk hematoma and arterial injuries ${ }^{24}$. If occur an inadvertent arterial puncture, the external compression is more efficient and less uncomfortable. Many patients prefer femoral access for aesthetic reasons because multiples prior biopsies can lead to keloid formation that is visible at cervical region.

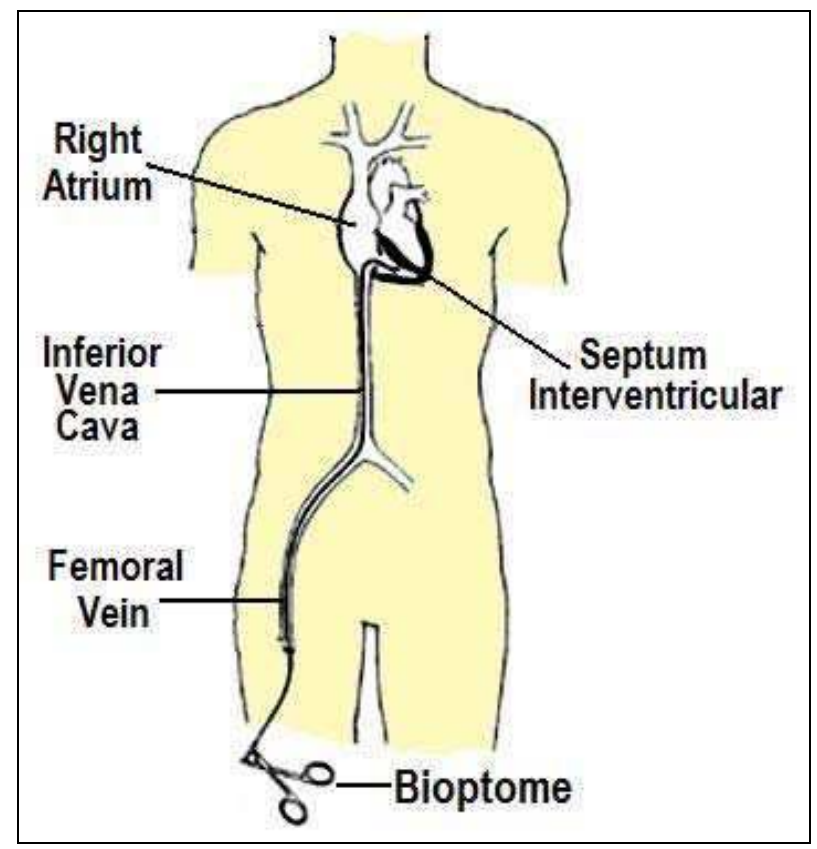

Fig. 6. Endomyocardial biopsy performed through left femoral vein. The bioptome advances by inside of the long sheath that runs along the inferior vena cava, passes through the tricuspid valve until the right side of the interventricular septum

It should be emphasized that inguinal region is potentially contaminated and this way the care with asepsis must be redoubled. Inguinal region should be widely shaved and washed with antiseptic solution before the usual surgical preparation. This considerations have more relevance to patients underwent to heart transplantation for increased susceptibility to infections.

As disadvantage the femoral access should be noted the need for a pre-shaped long sheath with curvature angle of 135-degree or catheter guidance to facilitate the direction of bioptome across the tricuspid valve. This approach may offer more difficulty to withdraw of 
myocardial specimens of an appropriate region of septum as well as fragments of larger size because the device is thinner. Moreover this long sheath increases the risk of lead to clots and deep venous thrombosis.

The operator may have the sensibility reduced by femoral approach because the trajectory of bioptome is long and may increase the ventricular perforation risk. Therefore, it is very important that the patients remain supine for approximately 2 to 4 hours after sheath removal to prevent bleeding.

In 2008, Holzmann et al., reported experience with 3048 biopsy only for femoral approach and had the following complications: pericardial tamponade with pericardiocentesis in $0.08 \%$; permanent complete AV block with permanent pacemaker required in $0.04 \%$; AV block III temporary requiring atropine and temporary pacemaker in $1.47 \%$; small pericardial effusions in $0.74 \%$; and persistent atrial fibrillation with cardioversion in $0.18 \% 25$.

\subsection{Femoral arterial approach}

The left ventricular biopsy is indicated only in specials situations because the right ventricular biopsy is sufficient to study of most cardiomyopathies. Left ventricle biopsy has more importance in the diagnosis of intracardiac masses than in cardiomyopathies assessment.

The guidewire used is long and advances through abdominal aorta retrogradely until into left ventricular cavity. After, this guide helps a pigtail catheter or pre-shaped sheath to be positioned into ventricular cavity too. In left ventricular biopsy is sufficient guide the bioptome away from mitral valvular apparatus because all walls are equally thick.

It must be dispensed much attention to inadvertent entry of air into the system for arterial embolism risk. During the procedure the sheath is washed continuously with heparin diluted into saline solution to avoid thrombus formations and embolism.

\subsection{Heterotopic heart approach}

For heterotopic heart transplantation, the donor right atrium is located into right hemithorax. Heterotopic heart approach requires a special strategy to achieve the donor right ventricle. The connection of the hearts may be performed between the anastomosis combinations of flowing donor-recipient structures vena cava and right atria. Metallic clips are put above and below that anastomosis to identification the bioptome entry site into donor heart. Right internal jugular vein remains the preferential route of approach. The other venous access may be used with the following order of increasing difficulty: left subclavian, left internal jugular, right subclavian, and finally femoral vein with much more difficulty.

Two-dimensional echocardiography offers good guidance in expert hands however with the fluoroscopy seems be easier. Figure 7 shows different stages in endomyocardial biopsy performing on heterotopic heart transplantation.

\section{Guidance for endomyocardial biopsy}

Endomyocardial biopsy usually is performed safely under fluoroscopic guidance because it provides information to the operator about the course of the bioptome and site of biopsy. Fluoroscopy presents several advantages because is widely known; easy handling, safe 
method, allows complete visualization of the procedure, and does not require an additional operator to biopsy achievement. It is the most accepted method and universally widespread.

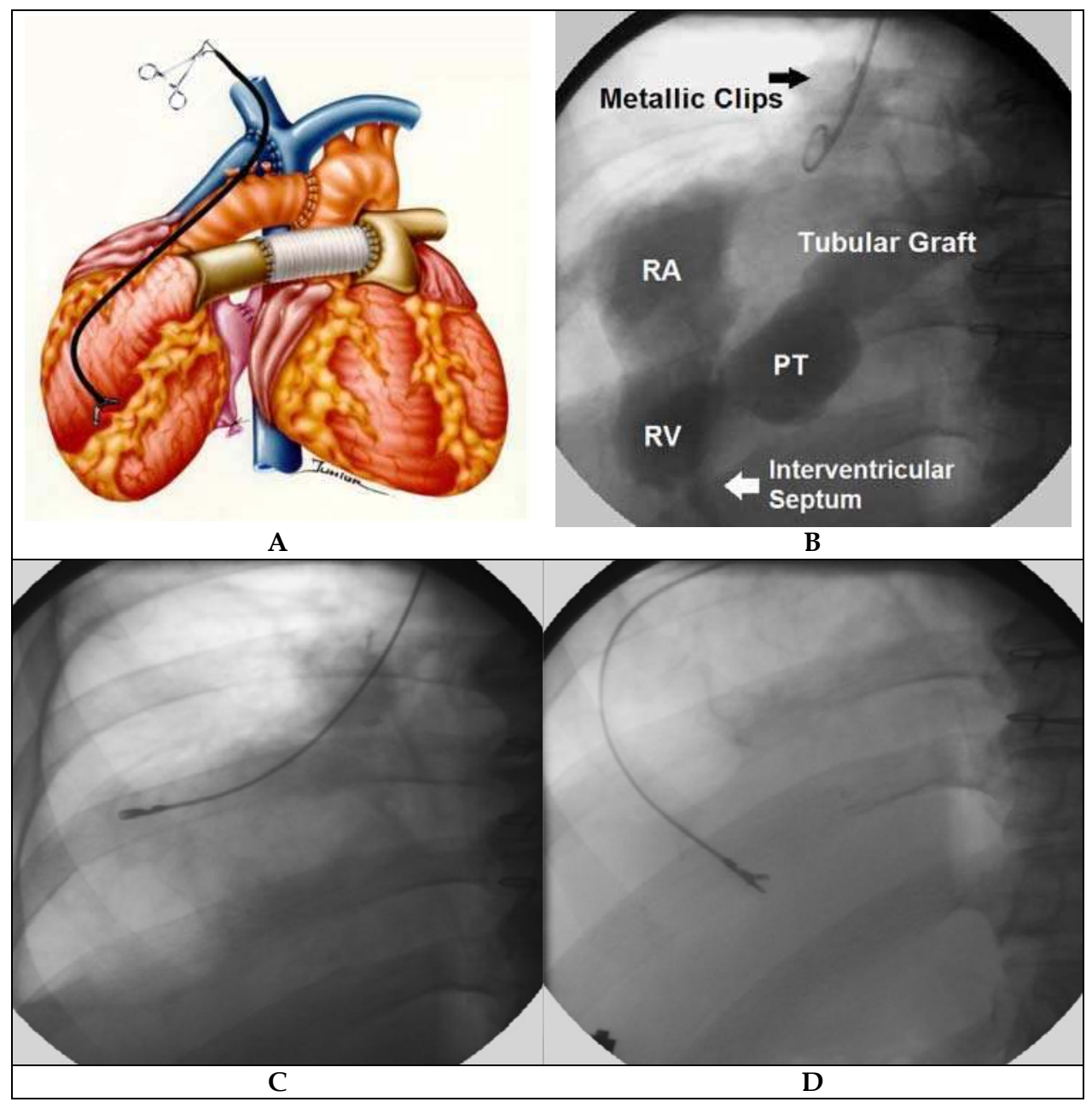

Fig. 7. A - Illustration showing bioptome trajectory during the performing of the endomyocardial biopsy on heterotopic heart transplantation. B - Contrast injection into graft superior vena cava. In superior vena cava anastomosis was placed metallic clips for easy identification of the bioptome entry site into cardiac graft. C - Inside the right atrium the bioptome tip tends to move away from the tricuspid valve. D - After rotating 180 degree the bioptome reaches the interventricular septum. Sometimes the forceps opening may offer resistance by trajectory tortuosity of bioptome

Other noninvasive methods may offer additional information about anatomic aspects and improved guidance of the bioptome ${ }^{26}$. For example, computed tomography may be used to 
assess the angle of the intraventricular septum relative to the superior vena cava or inferior vena cava, and cardiac magnetic resonance imaging may be of value to detection of a focal disease process may identify the area of the left or right ventricle that would be most likely to demonstrate the underlying pathological process. These methods have more application to guide biopsy with needle on investigation of the extracardiac thoracic mass.

\subsection{Endomyocardial biopsy guidance by echocardiography}

In this chapter we give more emphasis to two-dimensional echocardiography as guidance method for endomyocardial biopsy realization as well as hybrid method i.e. association of both methods for special situations.

In 1983, Hanley et al., published the use of echocardiography to guide endomyocardial biopsy in diagnosis of the left ventricle melanoma ${ }^{27}$.

In 1984, Piérard et al. reported the use of two-dimensional echocardiography as bioptome guidance method during the endomyocardial biopsy ${ }^{28}$. In the same year, Copeland et al., extended this procedure to investigation of intracardiac mass ${ }^{29}$.

In 1985 Williams et al., described the use of the two-echocardiography as guide to endomyocardial biopsy with successful in 83 patients being that in $96 \%$ of the cases was possible visualize the bioptome entering into right atrium, crossing the tricuspid valve, and advancing to the right ventricular apex and free wall ${ }^{30}$.

The echocardiographic technique without fluoroscopy has been used primarily to critical patients that cannot go to catheterization room, present contraindication for radiation or to biopsy intracardiac masses. In contrast to fluoroscopy and angiography, echocardiography is able to provide direct assessment of soft tissues and heart anatomy, and can assess the relationship between catheters or devices and adjacent structures.

Some operators use fluoroscopy and echocardiography in combination, also called hybrid method, to enhance entry into the right ventricle and direction of the bioptome. Threedimensional echocardiography may enhance visualization and reduce the reliance on radiographic imaging in the future.

Endomyocardial biopsy technique employs routinely the fluoroscopy to guide the bioptome very easily and with few adverse effects. In most cases, when there is high risk to transfer the patient at catheterization room or contraindication to use of fluoroscopy as in the pregnancy the echocardiography is very practical. Sometimes the transthoracic or transesophageal echocardiography are useful to confirm the position of intracardiac tumors but also to guide the bioptome for providing two or three-dimensional images.

Two-dimensional echocardiography advantages over other imaging modalities are equipment mobility, X-ray elimination, and offer in real time image during all procedure. It can be recorded at the bedside, into cardiac catheterization laboratory, cardiovascular intensive care unit, emergency room-indeed, any place that can accommodate a wheeled cart. It provide in real time images with adequate spatial orientation and anatomic definition. It is helpful in the cardiomyopathy diagnosis, intracardiac masses visualization, intracardiac catheters detection, and in the catheter placement and localization mainly in a pediatric population. However, it has as main disadvantage the necessity of a specialist operator becoming the process more expensive.

The most advantage with use of the two-dimensional echocardiography to guide endomyocardial biopsy is the possibility of realize the procedure to bedside and perhaps to 
may reduce the risk of perforation by a better anatomic definition of the myocardial sampling site. It permits sampling from different ventricular sites giving preference to the septum. Table 4 resumes advantages and disadvantages of endomyocardial biopsy guided by two-dimensional echocardiography.

\section{Advantages}

- It does not require the use of hemodynamic laboratory.

- Both patient and operator are not exposed to radiation.

- As two-dimensional echocardiography apparatus is portable the exam can be realized in intensive care unit, surgical room or even in the hemodynamic laboratory.

- It allows the realization of hybrid exam.

- Biopsy samples can be obtained from different site such as upper interventricular septum or middle, apex, and free wall, which increase the diagnostic yield.

- More accuracy to achieve the bioptome on intracavitary tumor mass.

\section{Disadvantages}

- It requires an operator specialized in echocardiography.

- $\quad$ Lack of window for viewing.

Table 4. Advantages and disadvantages two-dimensional echocardiography to guide endomyocardial biopsy

In our institution endomyocardial biopsy and Gallium-scintigraphy are the main methods to rejection control and Chagas' disease reactivation after heart transplantation, and research too $31-39$. The two-dimensional echocardiography has been used in last 25 years to guide endomyocardial biopsy examination with emphasis in critical patients with cardiomyopathy or after heart transplantation; to help in the visualization of the intracardiac tumors' position and in patients that cannot go at catheterization room ${ }^{40,41}$.

The patient is putting in supine position and the transducer is placed at the point of maximal impulse of the heart this way is possible obtain cardiac image in four chamber. This position offers the best view to follow the bioptome into cardiac chambers until interventricular septum. The transducer may be then moved medially in the same plane until it lay over the right ventricular apex.

After the heart global echocardiographic evaluation with propose of studied cardiac chambers and ejection fraction, the transducer was placed at the subcostal area apex and kept the image with apical four-chamber view. This position provides better image to guidance and accompaniment of the exam, and allows observing very well the movements of the bioptome extremity inside of the heart. It is possible identify the passage of bioptome within the superior vena cava, right atrium, crossing the tricuspid valve to reach the interventricular septum right side. 
An echocardiographic-dense image identifies the bioptome and the forceps removing the fragments of the interventricular septum. Contrast saline solution injection into venous system by jugular vein improves the cardiac chambers identification.

Once contact with the endocardium is confirmed by two-dimensional echocardiography, the bioptome is withdrawn 1 to $2 \mathrm{~cm}$ and its jaws were opened. After, the bioptome is advanced slowly to engage the endocardium. Gentle forward pressure is maintained while the jaws are closed.

In each exam was removing between 5 to 7 myocardial specimens for histopathological analysis. The bioptome containing the specimen is removed by gentle traction on the shaft.

Recently, we published our experience with the use of two-dimensional echocardiography as a guidance method to performance of endomyocardial biopsies. We avoided the withdrawal from myocardial samples of right ventricle free wall by higher risk of perforation ${ }^{40,41}$. The preferred route of access for bioptome percutaneous introduction was the right internal jugular vein with $8.5 \mathrm{Fr}$ introducer in $62(81.6 \%)$ biopsies, left internal jugular in $11(14.5 \%)$ and femoral vein in $3(3.9 \%)$. The guide catheter was useful in lots of situations mainly when femoral vein was the access route.

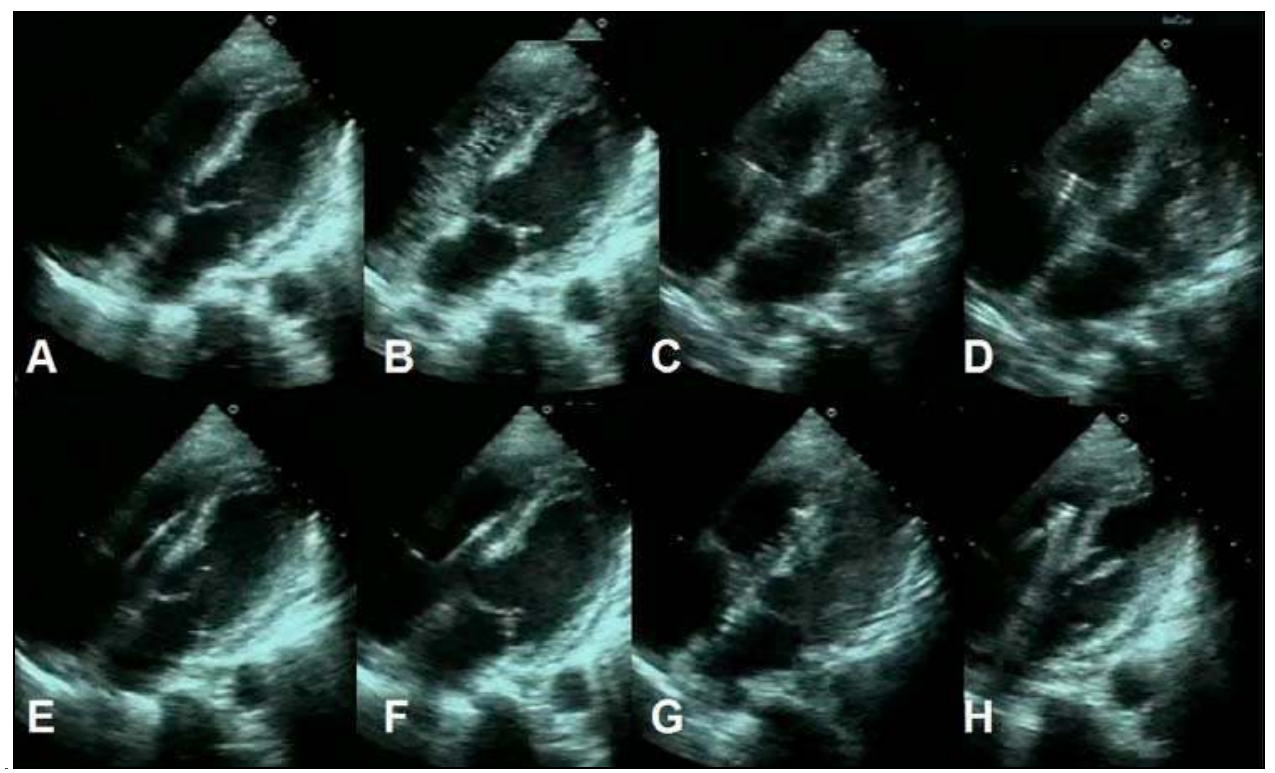

Fig. 8. Sequential images of the endomyocardial biopsy guided by two-dimensional echocardiography. A - Apical four-chamber view. B - Contrasted image obtained by saline solution injection. C - Bioptome tip on the tricuspid valve. D - Bioptome passing across tricuspid valve. $\mathrm{E}$ - Bioptome advancing against middle of the interventricular septum. F Bioptome withdrawing myocardial fragment. G - Bioptome withdrawing myocardial fragment at apex. $\mathrm{H}$ - Bioptome coming out the right ventricle

In patients who needed of the continuous invasive cardiac monitoring the Swan-Ganz catheter is easily installed after biopsy by echocardiography too. Hybrid guidance with 
fluoroscopy and two-dimensional echocardiography was very useful to carry out the bioptome with more safety during the learning period and in patients with cardiac tumor.

Heart transplantation operative technique, biatrial or bicaval, was not impeditive factor to realize the endomyocardial biopsy two-dimensional echocardiography guidance; however may have difficulty if the vena cava anastomosis had stenosis. The Figure 7 shows details of an endomyocardial biopsy image guided by two-dimensional echocardiographic in patient after heart transplantation by bicaval technique.

Two-dimensional echocardiography advantages over other imaging modalities are equipment mobility, X-ray elimination, and offer in real time image during all procedure. It can be recorded at the bedside, into cardiac catheterization laboratory, cardiovascular intensive care unit, emergency room-indeed, any place that can accommodate a wheeled cart. It provides in real time images with adequate spatial orientation and anatomic definition. It is helpful in the cardiomyopathy diagnosis, intracardiac masses visualization, intracardiac catheters detection, and in the catheter placement and localization mainly in a pediatric population. However, it has as main disadvantage the necessity of a specialist operator becoming the process more expensive.

In 2004, Bedanova et al. reported experience with 1,262 biopsies collected under echocardiography guidance in 156 patients and only in 11 patients there was conversion to X-ray guidance and no case of significant tricuspid regurgitation was related due to biopsy ${ }^{42}$.

After our learning period, the procedure duration time with echocardiographic guidance was comparable with fluoroscopy, between 10 and 15 minutes. The percutaneous right jugular vein approach was more employed due to its facility in offer few curves during the bioptome advance and both models can be used with guide catheter or sheath. In patients with artificial cardiac pacing the puncture was performed on an opposite side.

In our series, the surgical technique of the heart transplantation did not offer additional difficulties to endomyocardial biopsy by two-dimensional echocardiography guidance agreement with other investigations. Difficulties to progression of the bioptome occur frequently when there is severe stenosis at the site of the superior vena cava anastomosis.

Recently the use of real-time transthoracic three-dimensional echocardiography in endomyocardial right ventricular biopsies has been investigated both in children as in adults with easiness and safe perhaps until with more benefits ${ }^{43}$.

In experienced hands to accomplish endomyocardial biopsy by fluoroscopy the learning will be easier with two-dimensional echocardiography as orientation guide. The view by fluoroscopy is in the frontal plane (or coronal plane) being possible following the bioptome advance until there occurs transition of superior or inferior vena cava to right atrium, and the entry into right ventricle across tricuspid valve. The view by two-dimensional echocardiographic is in the transverse plane and the transducer is then located in the subcostal position, and a short-axis plane is visualized, showing the junction between the inferior vena cava and the right atrium. If the femoral vein approach is used, the bioptome can be seen entering the right atrium from the inferior vena cava.

When the forceps enters the right atrium, the transducer is rotated to obtain at frontal plane the subcostal four-chamber view that is the more appropriate (Figure 1). The tricuspid leaflets are easily visible by two-dimensional echocardiography and helps the operator pass the bioptome across valve with minimal trauma. The bioptome advances under 
echocardiographic control and is seen crossing the tricuspid valve and entering the right ventricular cavity.

Into the right atrium, an anterior counterclockwise rotation helps guide the bioptome overcome the tricuspid valve. This maneuver must be performed delicately by atrium perforation risk or injuries on valvar apparatus. Generally, the primary positioning is not satisfactory, and the catheter must be manipulated using two-dimensional echocardiography to position the tip optimally, in front of the interventricular septum. Further counterclockwise rotations straighten the curve and orient the bioptome to central ventricular septum.

Under two-echocardiography is possible withdraw myocardial fragments of all septum region and avoiding the ventricle free wall.

The most appalling during the endomyocardial biopsy accomplishment is the perforation of the right or left ventricle with cardiac tamponade by its high morbidity with death risk, especially if an inexperienced team does the manipulation. Sometimes it has been observed by fluoroscopy dislocation of the tip of the bioptome until the cardiac apex and is very difficult differentiating between apical portion septum and the free wall. These are the situations of more risk of the ventricular perforation mainly in dilated cardiomyopathies.

It is probably that the endomyocardial biopsy guidance by two-dimensional echocardiographic may reduce the complications incidence by providing a better anatomic view of the adequate site where the specimens must to be withdrawn, from the septum and not from the right ventricular free wall.

On the other hand, by two-dimensional echocardiography is possible adequately distinguishes the septum from the right ventricular free wall. It also permits patient followup after the procedure and immediate detection of complications such as pericardial effusion or the appearance of thrombus. Sometimes it is possible to identify the opening and closing of the bioptome jaw (Figure 5).

The local pain, hematoma and other minor complications may be more frequents and are related with the puncture difficulties.

\subsection{Risks of the endomyocardial biopsy}

The most potential complications due to endomyocardial biopsy occur during the procedure and the diagnosis or the suspect diagnostic is done also during the intervention period. Occasionally, the injuries due to endomyocardial biopsy have clinical manifestations late and during the intervention there was not any lesion suspect.

Main complications are ventricular perforation and tamponade cardiac; pneumothorax, hemothorax or both; cervical hematoma or mediastinal; ventricular arrhythmias or supraventricular; transitory cardiac block; carotid puncture or femoral; transitory phrenic nerve paralysis; pain; and unsuccessful puncture or guidewire progression. Except ventricular perforation the others may be more frequent however are considered benign complications and rarely put the patient in life risk.

Endomyocardial biopsy is a simple procedure but non-free of risk and the ventricular perforation followed of tamponade is the most terrible of them because the mortality is related with this severe complication. Patients with coagulopathies, increased right ventricular systolic pressures, recent receipt of heparin, or right ventricular enlargement seem to be at higher risk. 
Every center that performs endomyocardial biopsy must have available echocardiography because is useful to confirm pericardial effusion and should be performed whenever the operator suspects of ventricle perforation even before the patient leaves the catheterization room. This terrible complication may manifest initially with lightweight chest discomfort and without cardiovascular shock evident and that is getting worse due to the injury degree and the pericardial effusion intensity.

Immediate pericardiocentesis and the capability to surgically evacuate the pericardial space should be available at centers that perform endomyocardial biopsy. The right ventricle is more susceptible because the wall has about of 1 to $2 \mathrm{~mm}$ thickness. In patient with dilated cardiomyopathy this complication is more severe because right ventricular wall is thinner.

To reduce the chance of perforation, the operator must always open the bioptome jaws before touching the ventricle wall to increase contact area and after few seconds close the forceps slowly. This maneuver allows the bioptome accommodate among the trabecular and withdraw a myocardial fragment gently. The procedure must be repeated to removal of 5 to 7 fragments.

The bleeding risk after perforation increases in patients with pulmonary hypertension or coagulopathies. Small perforations may have spontaneous resolution because right ventricle pressure is low.

The contact of the bioptome with ventricular wall or during withdraw myocardial fragment may generate temporary ventricular arrhythmias. Malign arrhythmias rarely occur and are related with cardiomyopathy gravity. In our experience with more of 10,000 biopsies there is only related one case which needed of the cardiac defibrillation for ventricular fibrillation as primary event. Same in cardiomyopathies severe risk of malignant arrhythmias sustained is very rare.

The risks of endomyocardial biopsy are related with clinical picture of the patient and the operator experience. Patients with cardiogenic collapse or unstable ventricular arrhythmias require most care and carry to catheterization room is not recommendable. In these cases endomyocardial biopsy guidance by echocardiography is highly suitable.

\begin{tabular}{|l|l|}
\hline \multicolumn{1}{|c|}{ Major complications } & \multicolumn{1}{c|}{ Minor complications } \\
\hline Haemopericardium / Tamponade & Chest pain (transient) \\
Mediastinitis & Nerve palsy \\
Pneumothorax / Air embolism & Rupture of chordae tendineae (small) \\
Pericardial fibrosis/thickening & Deep vein thrombosis \\
Thromboembolism & Haematoma \\
Myocardial infarction & Hypotension \\
Infectious transmission (hepatitis B/C) & $\begin{array}{l}\text { Vascular fistulae } \\
\text { Tricuspid or mitral valve damage with }\end{array}$ \\
possible severe regurgitation & $\begin{array}{l}\text { Electrocardiographic abnormalities } \\
\text { (transient) }\end{array}$ \\
\hline
\end{tabular}

Table 5. Complications of endomyocardial biopsies 
Complications average rate is variable in different centers due to service experience and of adopted criteria in the database construction. Rate complications will be greater the more extensive and detailed is the database. Complications incidence varies since values inferior to $1 \%$ until $7 \%$, being that the more severe injuries as well as the mortality do not exceed to $0.5 \%$. Table 6 shows the main complications at experience for different authors.

\begin{tabular}{|c|c|c|c|c|c|c|}
\hline Author & Olsen & $\begin{array}{l}\text { Fowles } \\
\text { and } \\
\text { Mason }\end{array}$ & Deckers & Han & Fiorelli & Fiorelli \\
\hline Year & & 1982 & 1992 & $2006^{*}$ & 2010 & $2011^{*}$ \\
\hline Biopsy number & 3097 & $n>4000$ & 546 & 90 & $1228^{* *}$ & 76 \\
\hline $\begin{array}{l}\text { Possible ventricular } \\
\text { perforation (pain) }\end{array}$ & & & $0.7 \%$ & & $0.0 \%$ & $0.0 \%$ \\
\hline Tamponade & & $0.14 \%$ & $0.5 \% * * *$ & $3.3 \%$ & $0.8 \%$ & $0.0 \%$ \\
\hline Hemo/Pneumothorax & & 3 cases & & & $1.1 \%$ & $0.0 \%$ \\
\hline Atrial fibrillation & & 3 cases & & & $0.1 \%$ & $0.0 \%$ \\
\hline Ventricular arrhythmia & & 1 case & $1.1 \%$ & $1.1 \%$ & $0.5 \%$ & $0.8 \%$ \\
\hline AV block permanent & & & & & $0.0 \%$ & $0.0 \%$ \\
\hline $\begin{array}{l}\text { Neurological } \\
\text { complications }\end{array}$ & & 1 case & & & $0.0 \%$ & $0.0 \%$ \\
\hline Vasovagal reaction & & & $0.4 \%$ & $2.2 \%$ & $0.0 \%$ & $0.0 \%$ \\
\hline $\begin{array}{l}\text { Prolonged venous } \\
\text { oozing after sheath } \\
\text { removal }\end{array}$ & & & $0.2 \%$ & & $0.0 \%$ & $0.0 \%$ \\
\hline Local pain & & & & $6.7 \%$ & $8.3 \%$ & $5.6 \%$ \\
\hline Puncture failure & & & & & $5.8 \%$ & $6.6 \%$ \\
\hline Tricuspid injury & & & & & $0.8 \%$ & $0.0 \%$ \\
\hline $\begin{array}{l}\text { Arterial puncture } \\
\text { during local anesthesia }\end{array}$ & & & $2.0 \%$ & & $3.1 \%$ & $2.8 \%$ \\
\hline Local hematoma & & & & & $3.7 \%$ & $5.3 \%$ \\
\hline Arteriovenous fistula & & & & & $0.1 \%$ & $0.0 \%$ \\
\hline $\begin{array}{l}\text { Superior vena cava } \\
\text { injuries }\end{array}$ & & & & & $0.1 \%$ & $0.0 \%$ \\
\hline Mortality & & & $0.4 \%$ & $0.0 \%$ & $0.0 \%$ & $0.0 \%$ \\
\hline Total of complications & $1.55 \%$ & $<1 \%$ & $6.0 \%$ & $5.6 \%$ & $9.2 \%$ & $4.5 \%$ \\
\hline
\end{tabular}

Table 6. Complications after endomyocardial biopsy for different authors 


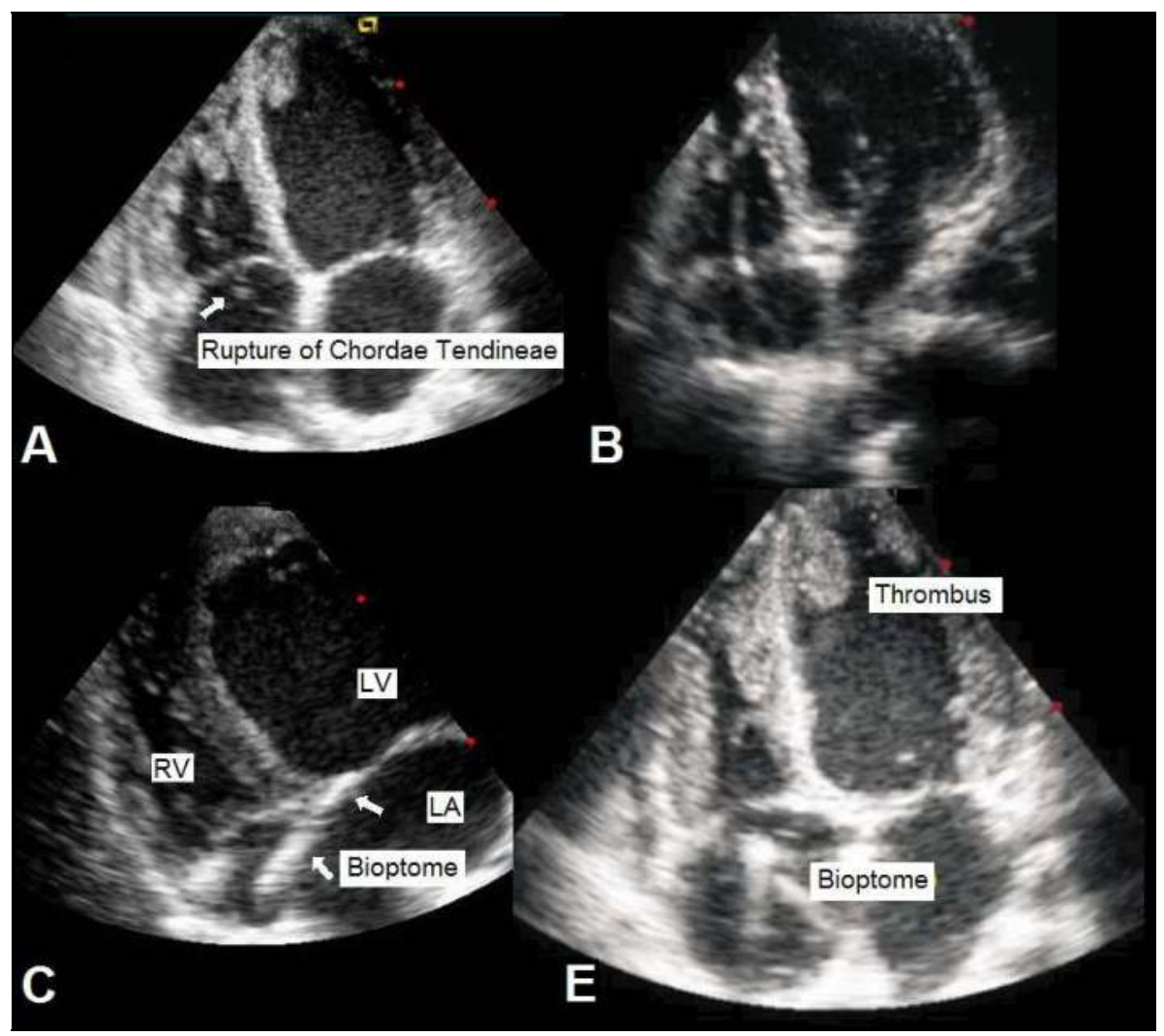

Fig. 9. A - Rupture of chordae tendineae due endomyocardial biopsy. B - Bioptome in normal position toward the interventricular septum. C - Bioptome inside coronary sinus. D Bioptome in normal position inside right atrium and left intraventricular thrombus finding echocardiographic

Courtesy of Dr. Arnaldo Rabischoffsky

\subsection{Conclusion}

Although there have been numerous studies comparing non-invasive imaging techniques to endomyocardial biopsy for the diagnosis of graft rejection, infiltrative disorders, and even intracardiac masses, there are still considerable limitations to these techniques. The endomyocardial biopsy remains the gold standard to assess and diagnose myocardial disease in the living patient.

The endomyocardial biopsy procedure is a safe, simple, and effective interventional procedure with a very low rate of morbidity and mortality. Fluoroscopy is the guide method to endomyocardial biopsy more used and safe; however in many times presents serious restrictions or same it cannot be utilized. Critical patients and pregnancy are good examples these situations.

Two-echocardiography is a fantastic recourse by information reliability, practicality and portable. Two-dimensional echocardiography is a special feature to guidance 
endomyocardial biopsies mainly in critically ill patients because it can be realized to bedside and without offers additional risk, and presents still advantages on the fluoroscopy. In special situations, the hybrid combination can be very useful mainly in intra-cardiac tumor cases.

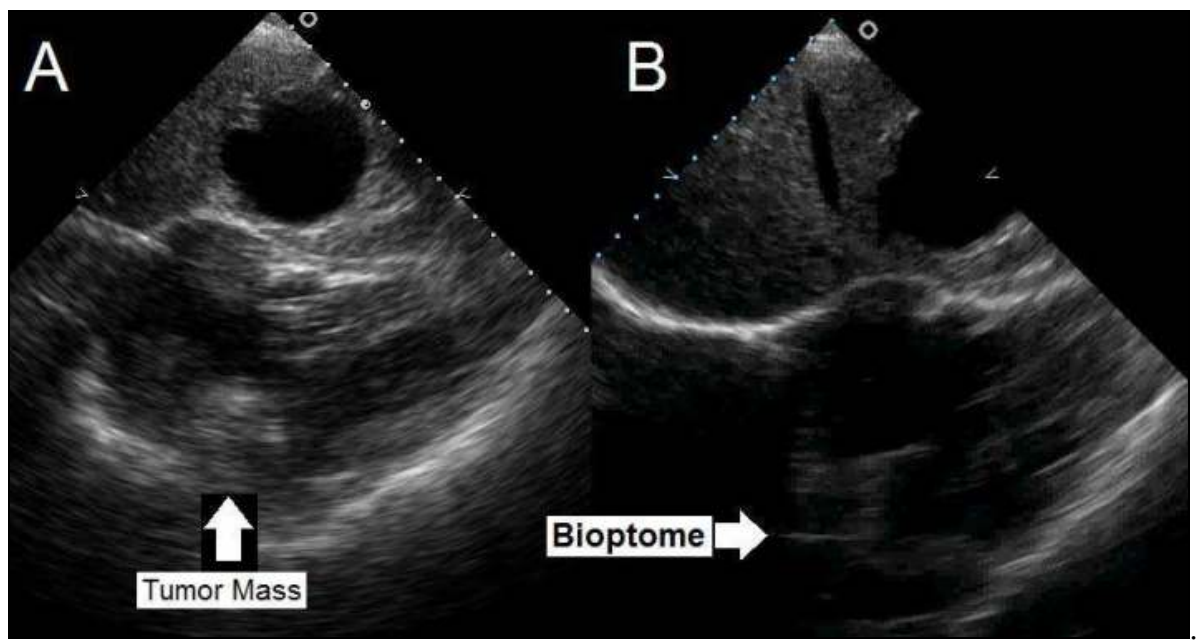

Fig. 10. A - Patient with tumor into right atrium confirmed by two-echocardiography. B Bioptome withdrawing myocardial fragment and anatomic pathological exam confirmed the presence of angiosarcoma

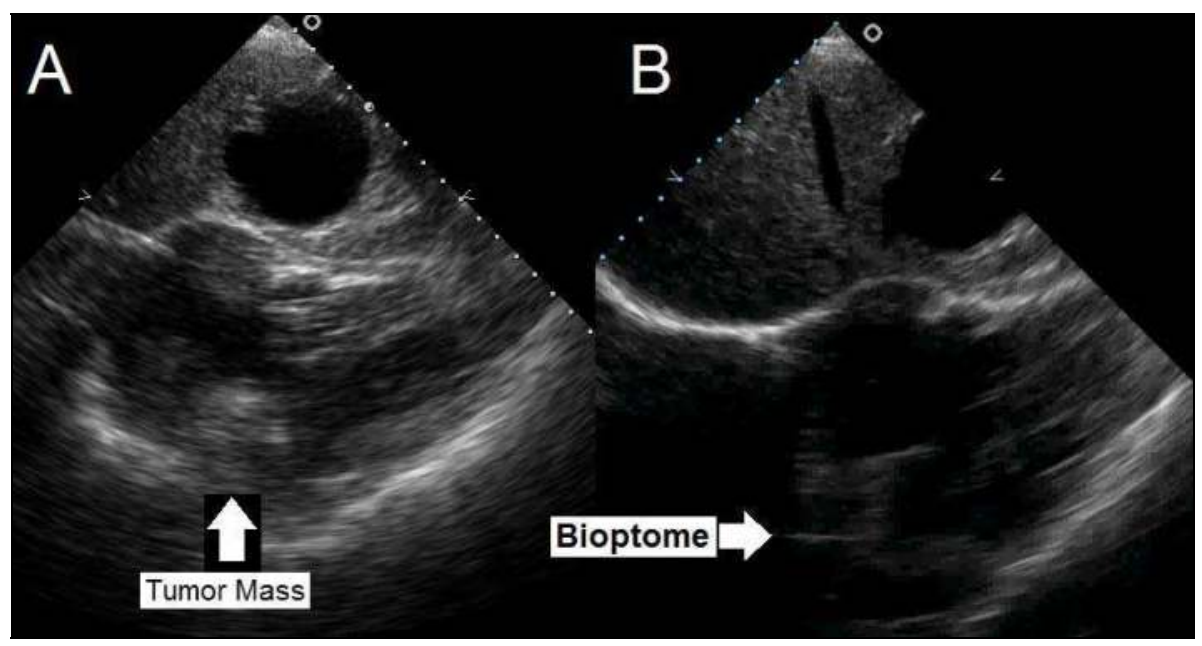

Fig. 11. A - Patient with tumor into right atrium confirmed by two-echocardiography. B Bioptome withdrawing myocardial fragment and the anatomic pathological exam confirmed the angiosarcoma diagnosis 


\section{Acknowledgements}

We thank to

To all members of the Echocardiography Department of Heart Institute of Sao Paulo University/Brazil for excellent care to patients and by working together that we have developed over the years which resulted in this publication.

To Dr. Arnaldo Rabischoffsky - Director of the Echocardiography Unit of the Pro-Cardiac Hospital, Rio de Janeiro / Brazil - for gently in provides images of his personal collection.

To Marcelo Fiorelli Alexandrino da Silva - Medical student of Sao Paulo University - for data collection.

\section{References}

[1] Elliott P, Arbustini E. The role of endomyocardial biopsy in the management of cardiovascular disease: a commentary on joint AHA/ACC/ESC guidelines. Heart. 2009;95:759-60.

[2] Pytlewski G, Georgeson S, Burke J et al. Endomyocardial biopsy under transesophageal echocardiographic guidance can be safely performed in the critically ill cardiac transplant recipient. Am J Cardiol 1994;73:1019-20.

[3] Cooper LT, Baughman KL, Feldman AM, Frustaci A, Jessup M, Kuhl U, Levine GN, Narula J, Starling RC, Towbin J, Virmani R. The role of endomyocardial biopsy in the management of cardiovascular disease: a scientific statement from the American Heart Association, the American College of Cardiology, and the European Society of Cardiology. Endorsed by the Heart Failure Society of America and the Heart Failure Association of the European Society of Cardiology. European Heart Journal 2007;28,3076-3093.

[4] Jackson CE, Gardner RS, Connelly DT. A novel approach for a novel combination: a trans-septal biopsy of left atrial mass in recurrent phyllodes tumour. Eur J Echocardiogr 2009;10:171-2.

[5] Abramowitz Y, Hiller N, Perlman G et al. - The diagnosis of primary cardiac lymphoma by right heart catheterization and biopsy using fluoroscopic and transthoracic echocardiographic guidance. Int J Cardiol 2007;118:e39-40.

[6] Raffensperger J, Driscoll J, Sutton G, et al: Myocardial biopsy. Arch Surg (Chicago) 1964;89:1021.

[7] Weinberg M, Egbert HF, Lydield J: Diagnostic biopsy of the pericardium and myocardium. Arch Surg (Chicago) 1958;76:825.

[8] Price KC, Weiss JM, Hata JM, et al: Experimental needle biopsy of myocardium of dogs with particular reference to histological study by electron microscopy. J Exper Med 1955;101:687.

[9] Bercu B, Heinz J, Chaudhry AS, et al: Myocardial biopsy -A new technique utilizing the ventricular septum. Am J Cardiol 1964;14:675.

[10] Timmis CG, Gordon S, Baron RH, et al: Percutaneous myocardial biopsy. Am Heart J 1965;70: 499.

[11] Leighton RF, Hamlin RL, Scarpelli DG, et al: Drill biopsy of the canine interventricular septum: A new cardiac catheterization technique. Am J Cardiol 1967;19:365.

[12] Bulloch RT, Murphy LM, Pearce BM: Intracardiac needle biopsy of the ventricular septum. Am J Cardiol 1965;16:227,. 
[13. Weinberg M, Fell Eh, Lynfield J. Diagnostic biopsy of the pericardium and myocardium. AMA Arch Surg. 1958;76:825-9.

[14] Sutton Dc, Sutton Gc. Needle biopsy of the human ventricular myocardium: review of 54 consecutive cases. Am Heart J. 1960;60:364-70.

[15] Timmis GC, Gordon S, Baron RH, Brough AJ. Percutaneous myocardial biopsy. Am Heart J. 1965;70:499-504.

[16] Sakakibara S, Konno S. Endomyocardial biopsy. Jpn Heart J. 1962;3:537-43.

[17] Bulloch Rt, Murphy Ml, Pearce Mb. Intracardiac needle biopsy of the ventricular septum. Am J Cardiol. 1965;16:227-33.

[18] Caves PK, Stinson EB, Graham AF, Billingham ME, Grehl TM, Shumway NE. Percutaneous transvenous endomyocardial biopsy. JAMA. 1973;225:288-91.

[19] Shirey EK, Hawk WA, Mukerji D, Effler DB. Percutaneous myocardial biopsy of the left ventricle. Experience in 198 patients. Circulation. 1972;46:112-22.

[20] Ali N, Ferrans VI, Roberts WC, Maswmi RA. Clinical evaluation of transvenous catheter technique for endomyocardial biopsy. Chest 1973;63;399-402.

[21] Richardson PJ. King's endomyocardial bioptome. Lancet. 1974;7859:660-1.

[22] Kawai C, Matsumori A, Kawamura K. Myocardial biopsy. Annu Rev Med. 1980;31:13957.

[23] Seldinger SI. Catheter replacement of the needle in percutaneous artenography: a new technique. Acta Radiol (Stockh) 1953; 36: 368-76.

[24] Anderson JL, Marshall HW. The femoral venous approach to endomyocardial biopsy: comparison with internal jugular and transarterial approaches.Am J Cardiol. 1984;53:833-7.

[25] Holzmann M, Nicko A, Kühl U, Noutsias M, Poller W, Hoffmann W, Morguet A, Witzenbichler B, Tschöpe C, Schultheiss HP, Pauschinger M. Complication rate of right ventricular endomyocardial biopsy via the femoral approach: a retrospective and prospective study analyzing 3048 diagnostic procedures over an 11-year period. Circulation. 2008;118:1722-8.

[26] Borchert B, Lawrenz T, Bartelsmeier M, Röthemeyer S, Kuhn H, Stellbrink C. Utility of endomyocardial biopsy guided by delayed enhancement areas on magnetic resonance imaging in the diagnosis of cardiac sarcoidosis. Clin Res Cardiol. 2007;96:759-62.

[27] Hanley PC, Shub C, SeWard JB, Wold LE. Intracavitary cardiac melanoma diagnosed by endomyocardial left ventricular biopsy. Chest 1983; 54:195-8

[28] Piérard L, El Allaf D, D'Orio V, Demoulin JC, Carlier J. Two-dimensional echocardiographic guiding of endomyocardial biopsy. Chest. 1984 Jun;85(6):759-62.

[29] Copeland JG, Valdes-Cruz L, Sahn DJ. Endomyocardial biopsy with fluoroscopic and two-dimensional echocardiographic guidance: case report of a patient suspected of having multiple cardiac tumors. Clin Cardiol. 1984;7:449-52.

[30] Williams GA, Kaintz RP, Habermehl KK, Nelson JG, Kennedy HL. Clinical experience with two-dimensional echocardiography to guide endomyocardial biopsy. Clin Cardiol. 1985;8:137-40.

[31] Higuchi ML, de Assis RV, Sambiase NV, Reis MM, Kalil J, Bocchi E, Fiorelli A, Stolf N, Bellotti G, Pileggi F, et al. Usefulness of T-cell phenotype characterization in endomyocardial biopsy fragments from human cardiac allografts. J Heart Lung Transplant. 1991;10:235-42. 
[32] Coelho V, Moliterno R, Higuchi ML, Guilherme L, Cunha-Neto E, Fiorelli AI, Kalil J. Gamma delta $\mathrm{T}$ cells play no major role in human heart allograft rejection. Transplantation. 1995;60:980-4.

[33] Bacal F, Veiga VC, Fiorelli AI, Bellotti G, Bocchi EA, Stolf NA, Ramires JA. Treatment of persistent rejection with methotrexate in stable patients submitted to heart transplantation. Arq Bras Cardiol. 2000;74:141-8.

[34] Benvenuti LA, Roggério A, Sambiase NV, Fiorelli A, Higuchi Mde L. Polymerase chain reaction in endomyocardial biopsies for monitoring reactivation of Chagas' disease in heart transplantation: a case report and review of the literature. Cardiovasc Pathol. 2005;14:265-8.

[35] Benvenuti LA, Roggério A, Freitas HF, Mansur AJ, Fiorelli A, Higuchi ML. Chronic American trypanosomiasis: parasite persistence in endomyocardial biopsies is associated with high-grade myocarditis. Ann Trop Med Parasitol. 2008;102:481-7.

[36] Fiorelli AI, Coelho GH, Lima JL, Lourenço DD, Gutierres P, Bacal F, Bocchi E, Dias RR, Stolf NA. Massive degeneration and atrophy of the native heart after heterotopic transplantation: a case report. Transplant Proc. 2009;41:965-6.

[37] Bacal F, de Freitas AF Jr, Moreira LF, F orelli AI, Mangini S, Abuhab A, de Lima Oliveira J Jr, Santos RH, Stolf NA, Bocchi EA. Validation of a cutoff value on echo Doppler analysis to replace right heart catheterization during pulmonary hypertension evaluation in heart transplant candidates. Transplant Proc. 2010;42:535-8.

[38] Benvenuti LA, Roggério A, Coelho G, Fiorelli AI. Usefulness of qualitative polymerase chain reaction for Trypanosoma cruzi DNA in endomyocardial biopsy specimens of chagasic heart transplant patients. J Heart Lung Transplant. 2011; [Epub ahead of print].

[39] Fiorelli AI, Santos RH, Oliveira JL Jr, Lourenço-Filho DD, Dias RR, Oliveira AS, da Silva MF, Ayoub FL, Bacal F, Souza GE, Bocchi EA, Stolf NA. Heart transplantation in 107 cases of Chagas' disease. Transplant Proc. 2011;43:220-4.

[40] Fiorelli AI, Coelho GH, Oliveira JL Jr, Aiello VD, Benvenuti LA, Santos A, Chi A, Tallans A, Igushi ML, Bacal F, Bocchi EA, Stolf NA. Endomyocardial biopsy as risk factor in the development of tricuspid insufficiency after heart transplantation. Transplant Proc. 2009;41:935-7.

[41] Fiorelli AI, Coelho GB, Santos RH, Oliveira JL Jr, Aielo V, Benvenuti L, Oliveira AS, Da Silva MA, Chizzola PR, Costa R, Mathias W Jr, Bacal F, Bocchi EA, Stolf NA. Successful endomyocardial biopsy guided by transthoracic two-dimensional echocardiography. Transplant Proc. 2011;43:225-8.

[42] Bedanova H, Necas J, Petrikovits E, Pokorny P, Kovalova S, Malik P, Ondrasek J, Cerny J. Echo-guided endomyocardial biopsy in heart transplant recipients. Transpl Int. 2004;17:622-5.

[43] Platts D, Brown M, Javorsky G, West C, Kelly N, Burstow D. Comparison of fluoroscopic versus real-time three-dimensional transthoracic echocardiographic guidance of endomyocardial biopsies. Eur J Echocardiogr. 2010;11:637-43.

[44] Olsen EG. The value of endomyocardial biopsies in myocarditis and dilated cardiomyopathy. Eur Heart J. 1991;12 Suppl D:10-2.

[45] Rabischoffsky A. Echo-guided endomyocardial biopsy. Rev Bras Ecocardiogr 2008;21:2730. 
[46] Han J, Park Y, Lee H, Kang H, Kim H, Yang DH, Park HS, Cho Y, Chae SC, Jun JE, Park WH. Complications of 2-D echocardiography guided transfemoral right ventricular endomyocardial biopsy. J Korean Med Sci. 2006;21:989-94.

[47] Fowles RE, Mason JW. Myocardial biopsy. Mayo Clin Proc. 1982;57:459-61.

[48] Deckers JW, Hare JM, Baughman KL. Complications of transvenous right ventricular endomyocardial biopsy in adult patients with cardiomyopathy: a seven-year survey of 546 consecutive diagnostic procedures in a tertiary referral center. J Am Coll Cardiol. 1992;19:43-7.

[49] Han J, Park Y, Lee H, Kang H, Kim H, Yang DH, Park HS, Cho Y, Chae SC, Jun JE, Park WH. Complications of 2-D echocardiography guided transfemoral right ventricular endomyocardial biopsy. . J Korean Med Sci. 2006;21:989-94. 


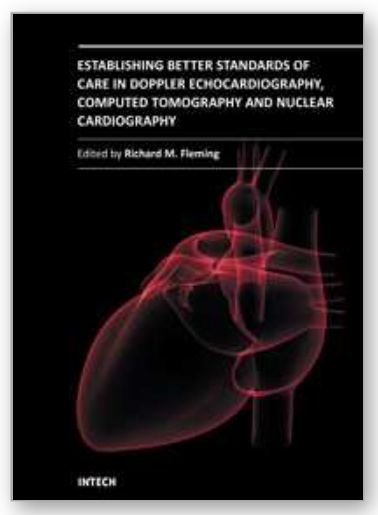

\author{
Establishing Better Standards of Care in Doppler \\ Echocardiography, Computed Tomography and Nuclear \\ Cardiology \\ Edited by Dr. Richard M. Fleming
}

ISBN 978-953-307-366-8

Hard cover, 260 pages

Publisher InTech

Published online 13, July, 2011

Published in print edition July, 2011

Since the introduction of Doppler Echocardiography, Nuclear Cardiology and Coronary CT imaging, clinicians and researchers have been searching for ways to improve their use of these important tools in both the diagnosis and treatment of heart disease. To keep up with cutting edge improvements in these fields, experts from around the world have come together in this book to provide the reader with the most up to date information to explain how, why and when these different non-invasive imaging tools should be used. This book will not only serve its reader well today but well into the future.

\title{
How to reference
}

In order to correctly reference this scholarly work, feel free to copy and paste the following:

Alfredo Inácio Fiorelli, Wilson Mathias Junior and Noedir Antonio Groppo Stolf (2011). Endomyocardial Biopsy Guided by Echocardiography, Establishing Better Standards of Care in Doppler Echocardiography, Computed Tomography and Nuclear Cardiology, Dr. Richard M. Fleming (Ed.), ISBN: 978-953-307-366-8, InTech, Available from: http://www.intechopen.com/books/establishing-better-standards-of-care-in-dopplerechocardiography-computed-tomography-and-nuclear-cardiology/endomyocardial-biopsy-guided-byechocardiography

\section{INTECH}

open science | open minds

\section{InTech Europe}

University Campus STeP Ri

Slavka Krautzeka 83/A

51000 Rijeka, Croatia

Phone: +385 (51) 770447

Fax: +385 (51) 686166

www.intechopen.com

\section{InTech China}

Unit 405, Office Block, Hotel Equatorial Shanghai

No.65, Yan An Road (West), Shanghai, 200040, China 中国上海市延安西路65号上海国际贵都大饭店办公楼 405 单元

Phone: +86-21-62489820

Fax: +86-21-62489821 
(C) 2011 The Author(s). Licensee IntechOpen. This chapter is distributed under the terms of the Creative Commons Attribution-NonCommercialShareAlike-3.0 License, which permits use, distribution and reproduction for non-commercial purposes, provided the original is properly cited and derivative works building on this content are distributed under the same license. 